\title{
From Sharing To Gifting: A web app for deepening engagement
}

\author{
Matt Adams \\ Blast Theory \\ Brighton, UK \\ matt@blasttheory.co.uk \\ Ju Row Farr \\ Blast Theory \\ Brighton, UK \\ ju@blasttheory.co.uk
}

\author{
Jocelyn Spence \\ Mixed Reality Lab \\ University of Nottingham, UK \\ jocelyn.spence@nottingham.ac.uk \\ Steve Benford \\ Mixed Reality Lab \\ University of Nottingham, UK \\ steve.benford@nottingham.ac.uk
}

\author{
Sarah Clark \\ Blast Theory \\ Brighton, UK \\ sarah@blasttheory.co.uk \\ Nick Tandavanitj
Blast Theory
Brighton, UK
ick@blasttheory.co.uk
}

\section{INTRODUCING GIFT}

Visitors currently use social media to share their experiences in museums, but these interactions are often short, quick and superficial. Is it possible to transform the impulse to share into an act of generosity, deepening engagement with museum collections and creating new patterns of behaviour?

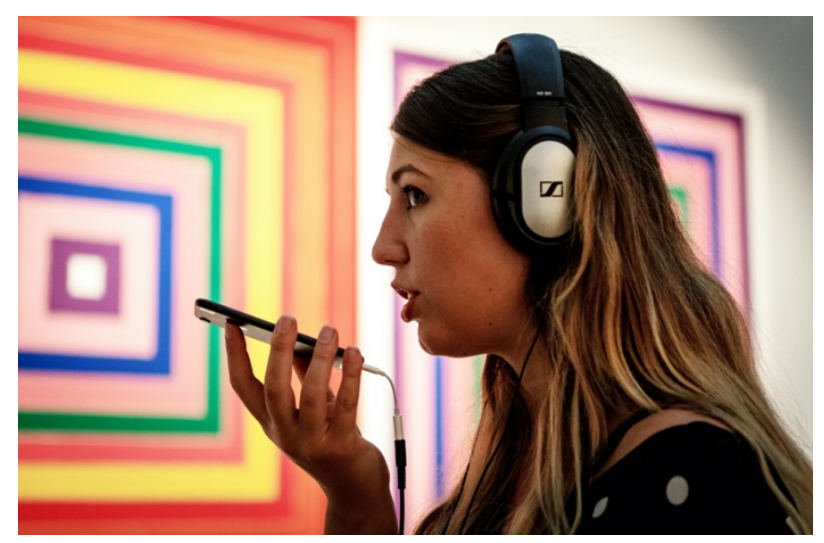

Figure 1: Museum visitor using the Gift web app at Brighton Museum

Gift is a web app that invites museum visitors to use their smartphone to create a digital gift. The app's narrator asks them to think of someone they care about before guiding them to explore the museum.

The tone is informal with minimal written instructions to free visitors from looking at their screen as they explore. With the person they've chosen in mind, visitors can select up to three objects in the museum, take a photo and make a voice recording for each, before sending their completed gift.
The work draws on the practice of gifting as a way to facilitate personalisation and social sharing in museums (e.g. Fosh et al. 2014), allowing visitors to define their own trajectory (Benford \& Giannachi 2011) through a museum's collection by creating a bespoke tour for a friend or loved one.

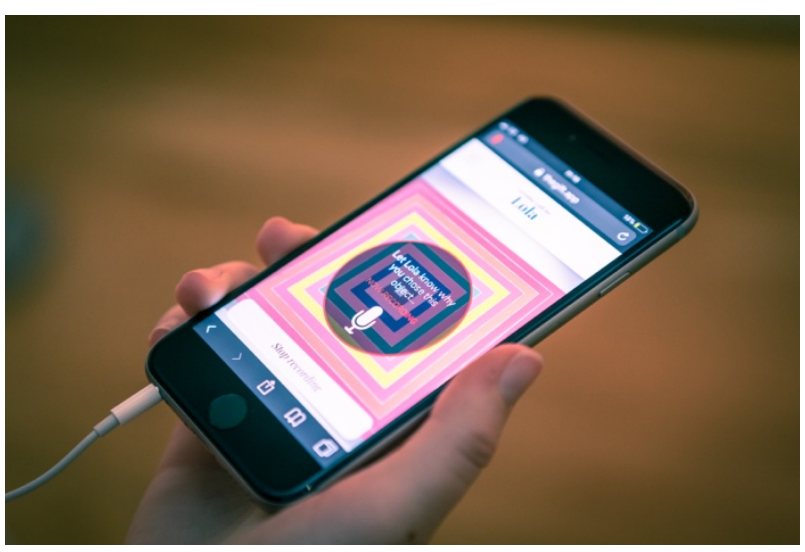

Figure 2: The web app's recording interface

\section{DESIGN GOALS}

Building on recent research working one-to-one with museum visitors to create bespoke tours (e.g. Fosh et al. 2014, Rennick-Egglestone et al. 2016), the goal we set was to explore how this format might be scaled via digital platforms to create a playful, social and personal experience that deepens visitors' engagement with museums' collections. In addition, the work sought to create a format that could extend museums' engagement via digital platforms and could integrate simply with a variety of museum environments, with the midsized, Western European city museum as a key point of reference. 


\section{DESIGN PROCESS}

The first prototype - a native Android app - was tested in July 2017, with a total of 16 users at Brighton Museum \& Art Gallery, a key partner in shaping and supporting our work. Creative and development teams from Blast Theory and the University of Nottingham worked on-site to iterate through a number of versions of the experience.

The second prototype was tested at Brighton Museum in July 2018 with 170 museum visitors over three days. A bespoke native app for iOS and Android, this prototype focused on creating a gift for someone you love. The deployment was supported by a large front-of-house team from Blast Theory and researchers from the University of Nottingham.

The second prototype provided a wealth of insights into users' experiences. In particular, it provided consistent evidence that the act of choosing to gift objects to someone to allowed visitors to explore the museum collection with 'new eyes' (Spence et al. 2019) while freeing them from the more prescriptive framing of traditional audio guides. However, it needed significant support, including resource-intensive engagement strategies, loan phones and headphones for visitors. This was judged to be impractical for long term deployments. In addition, the need to download an app and register an email was a clear barrier to taking part.

The final platform, now a web app, allows visitors to create a gift from their phone's own browser and send this via their own social media accounts. No registration or download is required, only scanning a QR code or entering a URL.

This version was deployed at Brighton Museum from June to October 2019 with minimal support from Blast Theory and has been followed by further deployments at the Munch Museum in Oslo and the Museum of Applied Arts in Belgrade. The platform is now open source and available for free or with support from Blast Theory (https://gifting.digital/giftexperience, EU Horizon 2020 grant No 727040).

\section{RECENT OBSERVATIONS}

Deployments of the web app in Brighton and Oslo have highlighted two emergent challenges:

\subsection{Onboarding}

Visitor uptake at Brighton Museum has shown to be highly dependent on verbal recommendations by the museum's front of house staff - falling off steeply when competing demands on the staff take priority. However, Brighton Museum's Digital Manager observes that the museum's ticket desk is a difficult place to engage visitors; busy staff sell tickets while visitors are still orienting themselves to the space and thus usually fail to notice postcards or other signage about the app. At Oslo's Munch Museum, the museum team decided to focus on postcards displayed around the exhibition itself for onboarding. While this resulted in a higher percentage of visitors beginning the experience, the completion rates for creating and sending gifts was lower. In the longer term, the Munch Museum plans to introduce mobile ticketing, providing a potential touch point to begin experiences such as Gift without the need to enter a URL.

\subsection{Children and teenagers}

Feedback from the second prototype indicated positive reactions to Gift from younger museum visitors. When in family groups, a child as young as seven created a gift assisted by a parent, while teenagers found the activity gave a focus to what might otherwise be an intimidating or uninteresting experience of deciding how to navigate a museum.

However, recent tests by the Munch Museum with school groups aged 10-11 revealed practical issues with the platform. Children in this age group often lacked a compatible device, while devices provided by the school blocked logging into personal social accounts. By contrast, Gift proved itself an engaging, accessible activity for 16-17 year-olds.

\section{REFERENCES}

Benford, S., and Giannachi, G. (2011) Performing mixed reality. MIT Press, Cambridge, MA; London.

Fosh, L., Benford, S., Reeves, S., and Koleva, B. (2014) Gifting personal interpretations in galleries. In: Proc. of the $\mathrm{CHI}$ Conference on Human Factors in Computing Systems, pp. 625-634.

Rennick-Egglestone, S. J., Brundell, P., Koleva, B., Benford, S., Roussou, M., and Chaffardon, C. (2016) Families and mobile devices in museums: designing for integrated experiences. ACM Journal on Computing and Cultural Heritage, 1(212), Article 11.

Spence, J., Bedwell, B., Coleman, M., Benford, S., Koleva, B. N., Adams, M., ... Lovlie, A. S. (2019) Seeing with New Eyes: Designing for In-the-Wild Museum Gifting. In: Proc. of the CHI Conference on Human Factors in Computing Systems, Paper 5. 